\title{
CAPITULO 92 \\ UMA ÓTICA EMPÁTICA E CRÍTICA PARA A QUESTÃO DAS \\ DROGAS: VISLUMBRANDO UMA ALTERNATIVA AO MODELO \\ PROIBICIONISTA
}

DOI 10.4322/978-65-995353-2-1.c92

\begin{abstract}
$\underline{\text { Natália Lopes Lima }}{ }^{1}$, Elias Emanoel Oliveira da Silva ${ }^{2}$, Yasmin de Sousa Vieira ${ }^{3}$, Ivelise Pereira dos Santos de Freitas ${ }^{4}$

1,2 Graduanda (o) em Direito pela Universidade Federal do Piauí- UFPI, Teresina, Piauí, Brasil. Email: natlialopes713@gmail.com. eliasoliver841@gmail.com.

${ }^{3}$ Graduanda em Direito pela Faculdade Maurício de Nassau- UNINASSAU, Teresina, Piauí, Brasil. Email: minsousa18@gmail.com.

${ }^{4}$ Graduada em Serviço Social pela Universidade Salvador- UNIFACS, Salvador, Bahia, Brasil.

Email: ivelisepereirafreitas@gmail.com.
\end{abstract}

\section{RESUMO}

O presente estudo tem como eixo central o modelo proibicionista sobre as drogas. Metodologicamente, adotou-se a revisão bibliográfica, de abordagem qualitativa e utilizando a pesquisa bibliográfica, com o fito, em um primeiro momento, de pontuar que o proibicionismo não consegue reintroduzir as pessoas viciadas na sociedade, a partir de uma abordagem focada em estudos sobre o vício em drogas, correlacionando-os a um exemplo de flexibilização do proibicionismo. Ademais, em segundo plano, o objetivo voltou-se para demonstrar a íntima ligação do sistema proibicionista com a penalização da população pobre e do ser negro. A partir disso, inferiu-se que a arquitetura penal dada à problemática não só dificulta a ressocialização dos viciados como também pune sobremaneira a negritude e a pobreza.

Palavras-chave: Proibicionismo; Sistema Penal; Portugal.

Área temática: Ciências Socias Aplicadas.

Email da autora principal: natlilopes713@gmail.com.

\section{INTRODUÇÃO}

As drogas estão presentes na sociedade humana desde os primórdios de sua existência. As finalidades são as mais diversas: práticas ritualisticas, tratamentos medicinais, atividades recreativas, etc. Ao longo da história os entorpecentes não foram proibidos, tampouco regulamentados, entretanto, a partir do século XX, há uma virada nessa conjuntura na medida em que a maioria dos países, incluindo o Brasil, encabeçados pelo modelo antidrogas 
estadunidense, adotou políticas severas focadas no proibicionismo das drogas (BORGES, 2016).

Nesse sentido, o objeto de estudo deste trabalho é o modelo proibicionista sobre as drogas, objetivando demonstrar que este não promove a reintegração dos dependentes na sociedade, sobretudo no contexto brasileiro, onde há a problemática do encarceramento em larga escala dos grupos subalternos e vulneráveis do tecido social, com participação ativa da polícia e da jurisdição estatal. Posto isso, a pertinência da temática está na capilaridade que alcança no meio social e com isso a importância de sua abordagem. Contudo, os debates relacionados ao tema são feitos de forma deturpada, com maior utilização do senso comum em detrimento do embasamento científico. Enxerga-se a droga como uma substância corruptível e que necessariamente levará a quadros de dependência, portanto, deve ser combatida com rigor, além do olhar de repulsa para com o viciado, tratando-o sob uma ótica criminal e não como um ser humano fragilizado que precisa de assistência e amparo.

Essas perspectivas enviesadas motivaram a construção do presente artigo, na tentativa de descontruir alguns pré-conceitos formados em detrimento das pessoas que se tornam dependentes e reforçar que o proibicionismo não é eficaz para diminuir o consumo e a circulação dos entorpecentes, conforme se propõe. Além disso, priorizou-se contextualizar o caso brasileiro, em que o encarceramento por crimes relacionados às drogas assume um viés racista e classista.

\section{METODOLOGIA}

Do ponto de vista metodológico, optou-se por uma revisão bibliográfica, com abordagem qualitativa de todos os trabalhos acadêmicos coletados, utilizando a pesquisa bibliográfica. Com isso, não foi delimitado um período temporal, mas, primeiramente, foram selecionadas aquelas pesquisas pertinentes em relação à temática de toxicodependência e que seguissem a linha de raciocínio de que uma pessoa se torna viciada não exclusivamente pelo consumo regular do entorpecente nem por ter uma suposta postura criminal, mas, devido, especialmente, aos contextos nos quais esse ser humano está inserido, para tanto, foram uitilizados os trabalhos de Alexander, Merhy e Silveira (2018) e Hari (2015). Ademais, ambicionando delinear um panorama geral da descriminalização das drogas feita em Portugal, a fim de demonstrar que uma alternativa ao paradigma repressivo surte reais efeitos no consumo de entorpecentes e nas problemáticas a eles relacionadas, foram empregadas as contribuições de Martins (2013) e Rodrigues Neto (2016).

E - book Tripé do Ensino Superior: Ensino, Pesquisa e Extensão 
Na segunda parte, preferiu-se trabalhos que comungassem da linha crítica do Direito Penal, compreendendo-o não apenas como um ramo do Direito que tão só define infrações penais e pune quem as transgride, mas também, como um instrumento de dominação social e que age de forma seletiva, conforme aponta Flauzina (2006). Desse modo, partindo dos pressupostos teóricos de Borges (2016), expõe-se que o intuito de proteger a saúde pública e afastar as pessoas das drogas, que sancionam sua criminalização, não são alcançados. Outrossim, com o mesmo pesquisador, analisou-se o modo de atuação seletivo da Instituição Policial, somado a isso, com as teses de Carvalho (2015), externou-se o agir dos atores judiciais e o quanto isso contribui para o aprisionamento de negros e pobres. Por fim, importante pontuar que foi estipulado um período temporal (referências dos últimos 5 anos) somente nos dados utilizados na pesquisa, a fim de melhor representar a realidade atual.

\section{RESULTADOS E DISCUSSÃO}

A questão das drogas ainda é percebida na sociedade com bastante preconceito e imbuída de julgamentos morais e culturais que enraizaram-se no debate público. A grande maioria da população associa o vício em narcóticos ao simples consumo reiterado da substância ilícita.Tal concepção encontrou terreno fértil entre o fim da década de 1960 e o início da década de 1980, em um contexto marcado tanto pelo endurecimento da política antidrogas iniciada pelo presidente estadunidense Richard Nixon e mantida pelos seus sucessores, quanto pela ebulição cultural e política do período, em que as drogas estavam ligadas às minorias racializadas e aos setores mais progressistas da sociedade americana, vistos como opostos aos valores cristãos anglo-saxônicos do branco estadunidense médio, o que tornava ainda mais justificável a ideologia proibicionista (BORGES, 2016).

Nessa seara, estudos realizados em laboratório nas décadas de 70 e 80 vieram a corroborar com a visão de que basta o uso regular de entorpecentes para sobrevir o vício. Os experimentos consistiam em disponibilizar a um rato engaiolado dois bebedouros, um com água pura e o outro com uma solução de morfina diluída em água. Os ratos submetidos a essa situação tiveram predileção pela solução aquosa de morfina. Estes desenvolveram vício na substância e alguns morreram em decorrência da overdose (ALEXANDER; MERHY; SILVEIRA, 2018). Para os cientistas, essa pesquisa foi considerada uma prova cabal de que o vício decorre apenas da ingestão constante de psicoativos, o que, por sua vez, mais que justificaria a política de repressão adotada pelo ocidente capitaneada pelos Estados Unidos. No entanto, o psicólogo Alexander e sua equipe notaram certas incongruências no experimento e decidiram replicá-lo 
com algumas alterações: ao invés dos ratos permanecerem em gaiolas pequenas e sem companhia, optaram por introduzi-los em uma gaiola muito mais espaçosa e colorida, com túneis e bolas para que os ratos pudessem se entreter. Além disso, foi inserido o fator convivência, no qual os ratos não mais estavam sozinhos, mas em grupos de 18 a 20 indivíduos, com metade destes sendo pertencente ao sexo masculino e a outra metade ao sexo feminino. Essa gaiola foi nomeada de Rat Park (ALEXANDER; MERHY; SILVEIRA, 2018). Como resultado desse experimento, os ratos consumiram uma quantidade relativamente menor da água com droga quando comparados aos isolados (menos de um quarto em quantidades absolutas). Além disso, nenhum deles morreu de overdose ou apresentou sintomas de abstinência após a interrupção do uso, enquanto no isolamento, todos os ratos apresentavam sintomas de abstinência antes que fossem reintroduzidos na gaiola e morressem de overdose (ALEXANDER; MERHY; SILVEIRA, 2018).

Nesse seguimento, o pesquisador Hari (2015), em seu livro "Chasing the Scream: the first and the last days of the war on drugs", abordou o famoso experimento de Bruce Alexander e buscou traçar paralelos com acontecimentos semelhantes na história humana. Segundo Hari (2015), o caso mais próximo de Rat Park ocorreu durante e após a Guerra do Vietnã, em que $20 \%$ das tropas americanas em solo vietnamita desenvolveram vício em heroína, droga da família dos opioides, a qual também compreende a morfina do experimento de Alexander com os ratos. Com o fim da guerra, as autoridades sanitárias dos Estados Unidos e a Drug Enforcement Administration (DEA)-Administração de Fiscalização de Drogas- ficaram receosos de que houvesse um aumento considerável no número de viciados em heroína nos EUA, no entanto, $95 \%$ dos toxicodependentes que voltaram para casa conseguiram se curar do vício em menos de um ano e de forma natural (HARI, 2015).

Nessa perspectiva, os experimentos do doutor Alexander e o estudo apresentado na obra de Hari (2015) trazem indícios de que a dependência transcende o aspecto químico e alcança outros determinantes, como o fator emocional e social. Ratos engaiolados e que são submetidos a poucos estímulos que sejam capazes de ativar os neurotransmissores do cérebro e descarregar hormônios de prazer e euforia em seus corpos são mais suscetíveis aos efeitos negativos das drogas, visto que estas também possuem ativos capazes de ligarem-se com os receptores de endorfina, dopamina, adrenalina, serotonina, dentre outros. Tanto os roedores presos em gaiolas pequenas quanto as tropas americanas no Vietnã enfrentavam situações de bastante estresse emocional e, portanto, buscaram a forma mais simples a sua disposição para prover a seus cérebros a quantidade demandada de neurotransmissores. O retorno dos soldados a suas casas e ao aconchego de suas famílias fez com que a imensa maioria deles debandasse do uso de 
heroína, o que, de maneira análoga, aconteceu com os ratos de Rat Park.

Destarte, o paradigma proibicionista age de maneira oposta, pois conferir um caráter penal à questão das drogas não ataca o real motivo pelo qual toxicodependentes tentam fugir de suas realidades. Por esse ângulo, o exemplo de Portugal ilustra que uma intervenção não proibicionista pode gerar consequências positivas no controle das drogas. O país ibérico presenciou um surto no consumo de psicoativos durante os anos que sucederam o fim da ditadura de Antônio Salazar, dado que, durante seu regime, foi promulgado o Decreto-Lei $n^{\circ}$ 420/70, o qual regulava a produção, o tráfico e o uso de tóxicos, contribuindo para a repressão ao consumo de drogas (RODRIGUES NETO, 2016). Devido ao fracasso do paradigma punitivo em Portugal, os mandatos governistas subsequentes ao de Salazar tentaram adotar políticas descriminalizantes. Após debates do governo, ao longo da década de 80 e 90, com os diversos setores da sociedade portuguesa, resolveu-se modificar a política em relação aos psicoativos, culminando na Lei ${ }^{\circ}$ 30/2000 (RODRIGUES NETO, 2016).

Com a referida lei, o país descriminalizou o consumo de todas as drogas (GREENWALD, 2009). Nesse ínterim, faz-se mister distinguir o significado de descriminalizar, legalizar ou despenalizar no que tange às drogas. Nas linhas de Greenwald (2009), descriminalizar quer dizer que as infrações saíram do âmbito penal e da justiça criminal, passando a ser tratadas na esfera administrativa. Quanto à despenalização, significa que o consumo de entorpecentes ainda existe como crime, porém, a pena privativa de liberdade é suprimida dentre as reprimendas penais cabíveis, aplica-se multa, liberdade condicionada, dentre outras. Na legalização, a venda, produção, posse ou consumo de drogas não sofre qualquer tipo de proibição.

Em Portugal, o uso, a compra e a posse para consumo próprio, embora ainda sejam condutas proibidas legalmente, deixaram de ser crime, desde que a quantidade não seja superior ao consumo médio individual durante 10 dias (RODRIGUES NETO, 2016). Com isso, a "virada de chave" no modelo português deu-se com o tipo de abordagem da problemática, priorizando alocar investimentos para políticas de desestímulo ao consumo, por meio da informação, redução de danos, como a troca de seringas para as drogas injetáveis, e a construção de mais centros de tratamentos, ao invés de punições (RODRIGUES NETO, 2016). O usuário não mais sofreria processos penais, passou a integrar a esfera da saúde pública, com vistas ao seu acolhimento e a um uso controlado e seguro das substâncias. Quando alguém portando/consumindo drogas fosse flagrado, não seria mais conduzido a uma delegacia, mas guiado a Comissão para a Dissuasão da Toxicodependência- integrada por dois profissionais que possuem experiência na temática de drogadição, além de um jurista- e após identificar a Pesquisa e Extensão 
pessoa, suas condições socioeconômicas, o modo de uso e o nível de dependência, essa comissão aplica as medidas cabíveis, que podem ser sanções administrativas, tratamento ou terapia (MARTINS, 2013), mas em nenhuma hipótese será aplicada a abordagem coercitiva (RODRIGUES NETO, 2016).

Conforme os resultados angariados por Portugal desde a implementação do referido diploma legal, percebe-se que o usuário deixou de ser um inimigo da lei e passou a ser inserido no sistema de saúde português e na sociedade. A cobertura do programa chegou a atingir quase 95\% dos toxicodependentes de Portugal e como resultado o país conseguiu que o uso de heroína e cocaína despencasse, reduzindo de $1 \%$ para $0,3 \%$ da população portuguesa. As contaminações por HIV entre os consumidores, um dos principais problemas em razão do uso da heroína injetável, caíram pela metade (eram assustadores 104 novos casos por milhão ao ano em 1999 e em 2015 passou a ser 4,2 casos a cada milhão de habitantes) e o encarceramento de pessoas por motivos associados às drogas diminuiu de $75 \%$ para $45 \%$, segundo dados extraídos da matéria de 6 de maio de 2019 no jornal El País e disponibilizados pela Agência Piaget para o Desenvolvimento (Apdes).

Ante o exposto, pode-se colocar que a associação entre entorpecentes e o necessário vício é algo equivocado, deve-se somar ao uso reiterado, o contexto socioeconômico e emocional que a pessoa está vivenciando. Por outro lado, há uma relação entre a flexibilização do modelo proibicionista e a eficácia em reduzir o número de dependentes, resultando em uma diminuição das consequências maléficas desse problema na sociedade. Desse modo, o proibicionismo falha, tanto em conceder uma rede de apoio às pessoas viciadas, integrando-as de fato na sociedade, quanto em conseguir conter a comercialização e difusão dos entorpecentes. No Brasil, a problemática das drogas ganha outros contornos, em vista da criminalização afetar seletivamente pessoas racializadas e periféricas.

Dando continuidade, as instituições criminais que executam a política repressiva sobre as drogas tomam como certo que empreender esse modelo proibicionista é válido porque o uso de drogas inevitavelmente leva a quadros de dependência, além de que, drogas desnaturam a mente humana podendo levar a pessoa a ter comportamentos criminosos (BORGES, 2016). Com isso, o porte e o comércio ilícito de entorpecentes devem ser duramente combatidos, em virtude de constituírem um perigo para a saúde do corpo social. No entanto, pode-se inferir que a proteção social a qual se propõe essa medida criminalizadora não ocorre na realidade. O que se observa é o uso do aparato repressivo do Estado em direção aos grupos mais vulneráveis da sociedade. Com contribuição da Instituição Policial e dos atores judiciais, o sistema que, em tese, deveria garantir a tão almejada segurança pública legitimadora da política de guerra às

\section{E - book Tripé do Ensino Superior: Ensino,} Pesquisa e Extensão 
drogas, acaba por produzir vítimas.

O paradigma proibicionista está fundado na salvaguarda dos interesses sociais, ao ter como objetividade jurídica a saúde pública, uma vez que esta configura-se como o polo passivo da dispersão do consumo de drogas (BORGES, 2016). Com isso, criminalizar o uso e o tráfico de psicoativos seria uma forma de protegê-la, dado que o consumo ou a disseminação de substâncias ilícitas (tráfico) caracterizam crime de perigo abstrato pela lesão presumida à saúde pública, visto que o seu uso pode desencadear quadros de dependência, ameaçando o bem-estar físico e psíquico dos seres humanos. Considerar a droga um esfacelador da vida social também é um discurso que respalda o paradigma proibicionista, por consequência, a sociedade demoniza as drogas, assim como aqueles que as consomem. Desse modo, a criminalização é a solução mais apropriada porque é vital agir contra essas substâncias “demoníacas" (BORGES, p. 36, 2016), seguindo a linha de apenas culpabilizar as pessoas por sua eventual dependência (MARTINS, 2013), desumanizando o usuário. Entretanto, como pontua Borges (2016), o modelo proibicionista não alcança os seus objetivos instituídos (como a desarticulação das estruturas das organizações criminosas que estão à frente do comércio ilícito de drogas e diminuir o consumo entre a população brasileira), o que se observa, na verdade, é uma atuação seletiva da máquina estatal no combate às drogas.

Segundo a ótica de Flauzina (2006), a seletividade é a marca estrutural do sistema penal, afirmando que este funciona de modo quantitativa e qualitativamente seletivo. Sob esse ângulo, o sistema penal é dirigido de acordo com uma perspectiva de não penalização de certos delitos e imunidade a determinadas pessoas, o que Flauzina denomina de seletividade quantitativa. Desse modo, o sistema penal é inepto a realizar o objetivo primordial para o qual foi criado: corrigir de maneira isonômica as perturbações mais graves que ocorrem no ordenamento jurídico e quem o perturba.

A seletividade qualitativa, a seu turno, está conectada à criminalização primária (quando o Poder Executivo ou Legislativo seleciona determinadas condutas, positivas ou negativas, que deverão merecer as reprimendas penais cabíveis) e a criminalização secundária, coordenada pela Polícia, promotores e os atores judiciais os quais direcionam o controle penal a um dado grupo social, o que reforça estereótipos criminais (FLAUZINA, 2006). Nessa linha, a atuação policial na repressão ao consumo e tráfico de drogas é um ótimo exemplo dessa seletividade penal. É certo que milhares de brasileiros praticam ambos os delitos; de todas as etnias, estratos sociais, faixas etárias e gêneros. Todavia, Borges (2016) nos alerta que a suspeita policial se volta esmagadoramente para pessoas negras e pobres. Nesse sentido, porque "as estatísticas criminais são indicativos [...] não dos grupos mais criminosos, mas daqueles mais 
criminalizados" (BORGES, p. 51, 2016) não se pode afirmar de modo algum que essa parcela do corpo social seja a que mais cometa esses ilícitos penais, mas tão somente que negritude e pobreza são fatores de vulnerabilidade para o encarceramento. Isso correlaciona-se ao fato de que pessoas negras e pobres são erroneamente associadas ao estereótipo de "bandido" e "marginal", criando a mácula sobre negros e periféricos de serem presumivelmente criminosos e, portanto, merecedores de todo o aparato repressivo estatal.

Coerentemente com essa visão, Carvalho (2015) evidencia que os dados referentes à taxa de aprisionamento permitem inferir a parcela importante de participação do Poder Judiciário no encarceramento em massa de pessoas negras. Em acordo com esse pensamento, os dados mais recentes compilados pelo Anuário Brasileiro de Segurança Pública de 2021 ilustram bem essa maior incidência da taxa de prisionalização sobre pessoas negras. Quanto à quantidade de pessoas encarceradas que tiveram suas informações de raça registradas (599.932 em 2020) referente ao período de janeiro e junho, 397.816 eram pessoas identificadas como negras, o que corresponde a 66,3\% do total e apenas 32,5\% dos encarcerados foram classificados como brancos ou 195.085 presos. Isso demonstra uma normalização do racismo nos órgãos de aplicação da pena e consequentemente na orientação do punitivismo estatal. Um dos pontos levantados pelo professor, a fim de analisar mais profundamente a contribuição dos magistrados para o encarceramento de negros, é a Lei de Drogas brasileira, porquanto seja um dos crimes que mais gera prisões, atrás apenas dos delitos patrimoniais (CARVALHO, 2015). Dado que a norma, não obstante despenalize o uso de substâncias ilícitas, não traz patamares mínimos objetivos de psicoativos portados pela pessoa que permita distingui-la como usuário ou como traficante (CARVALHO, 2015).

Esse trabalho de diferenciação fica a cargo, inicialmente, de policiais e muitos dos quais, em suas abordagens, costumam utilizar critérios raciais e socioeconômicos, colocando pessoas brancas de classe média ou mais abastadas na benesse de destinatárias finais das drogas, ainda que com elas sejam encontradas uma quantidade considerável de substâncias ilícitas que permita deduzir que seja para o comércio ilícito, por não terem o estereótipo de criminoso, e imputando aos negros periféricos a figura de traficante, mesmo que esses venham a ser apreendidos com uma pequena quantidade de drogas, por serem presumivelmente marginais (BORGES, 2016). Subsequentemente, a valoração judicial tende a corroborar com a imputação feita pelos policiais, em decorrência dos privilégios e posições de vantagens vivenciados pelos primeiros e da vulnerabilidade social sofrida pelos segundos.

Sob essa perspectiva, traficantes brancos de boa posição social conseguem suportar os honorários advocatícios de excelentes criminalistas para fazerem suas defesas técnicas e, com

\section{E - book Tripé do Ensino Superior: Ensino,} Pesquisa e Extensão 
isso, dificilmente são condenados pelo crime de tráfico de psicoativos. O que ocorre, nas raras vezes em que são punidos, é a desclassificação para usuários de drogas. Em contraponto a isso, jovens não brancos e desprovidos de recursos financeiros não podem arcar com os altos custos de um bom advogado criminal, além da carência de defensores públicos no Brasil (BORGES, 2016), dificultando o acesso dessas pessoas a um processo penal justo. Assim, o judiciário brasileiro segue a linha de castigar mais a negritude e a pobreza e dar imunidade às pessoas brancas e de maior poder aquisitivo. Logo, usuários negros presos em flagrante em um contexto de marginalização e fragilidade social são mais facilmente interpretados e posteriormente condenados por tráfico de entorpecentes.

\section{CONSIDERAÇÕES FINAIS}

Diante do exposto, é evidente que o modelo proibicionista falha em reinserir o dependente na sociedade, grande parte, devido aos estigmas produzidos em desfavor desse grupo e contra as drogas. Destarte, a ingerência penal da questão tolhe a capacidade do Estado em canalizar investimento público consciente para a construção de perspectivas reais e uma rede de apoio no âmbito da saúde, a fim de integrar de fato os viciados e assim tirá-los de suas “gaiolas solitárias” em que o único estímulo possível é a droga.

Outro aspecto a ser destacado é que a estrutura legal brasileira de combate às drogas justifica-se, de forma velada, pelo domínio sobre corpos negros e espaços povoados pelo contingente mais pobre dos centros urbanos do país, tendo em vista que mais facilmente são pessoas racializadas e despojadas de vantagens socioeconômicas que lotam os presídios brasileiros por essas práticas incriminadoras. Nessa linha, não olvidemos da contribuição da Instituição Policial e dos operadores do Direito para essa filtragem racial e social na consecução e posterior aplicação da Lei de Drogas, pois os critérios de distinção entre o usuário e o traficante são marcadamente étnico-raciais e classistas, o que deixa transparecer a seletividade do sistema penal.

Dessa forma, esse escrito buscou traçar alguns elementos que amparam uma política de drogas antiproibicionista, com especial olhar para os viciados e o desenvolvimento de um aparato social para estes em vez de repressão, além de pontuar o fator encarceramento em massa empreendido contra o segmento negro e pauperizado da sociedade brasileira. Nesse âmbito, quanto às limitações desse trabalho, pode-se destacar a não abordagem das dificuldades para a implantação de políticas públicas, sobretudo no Brasil, de abrandamento ao proibicionismo e consequentemente os aspectos que levam a manutenção dessa política criminal, o que pode ser desenvolvido e aprofundado em futuras pesquisas.

\section{E - book Tripé do Ensino Superior: Ensino,} Pesquisa e Extensão 


\section{REFERÊNCIAS}

ALEXANDER, B. K; MERHY, E. E; SILVEIRA, P. Criminalização ou acolhimento?. In: ALEXANDER, B. K. Dependência dos opiláceos: Rat-Park revisitado. Porto Alegre: Rede Unida, 2018. p. 19-57.

BORGES, S. S. da F.A eficácia invertida da guerra às drogas: gestão diferencial das ilegalidades e dominações sociais. 2016. 101 f. Monografia (Bacharel em Ciência Política) Instituto de Ciência Política. Universidade de Brasília, Brasília, 2016. Disponível em: https://bdm.unb.br/handle/10483/16858. Acesso em: 26 jun. 2021.

CARVALHO, S de. O encarceramento seletivo da juventude negra brasileira: a decisiva contribuição do Poder Judiciário. Revista da Faculdade de Direito da UFMG, n. 67, p. 623652, 2015. DOI: 10.12818/P.0304-2340.2015v67p623. Acesso em: 26 jun. 2021.

FBSP - Fórum Brasileiro de Segurança Pública. Anuário Brasileiro de Segurança Pública, São Paulo, 2021. Disponível em: https://forumseguranca.org.br/anuario-brasileiro-segurancapublica/. Acesso em: 15 jul. 2021.

FLAUZINA, A. L. P. Corpo negro caído no chão: o sistema penal e o projeto genocida do Estado brasileiro. 2006. 145 f. Dissertação (Mestrado em Direito) - Faculdade de Direito, Universidade de Brasília, Brasília, 2006. Disponível em:

https://repositorio.unb.br/handle/10482/5117. Acesso em: 26 jun 2021.

GREENWALD, G. Dependências - Só para Profissionais, 2009. Disponível em: http://www.dependencias.pt. Acesso em: 18 jul. 2021.

HARI, J. Chasing the Scream: The First and Last Days of the War on Drugs. Nova York: Bloomsburry Publishing, 2015.

LINDE, P. Como Portugal se tornou referência mundial na regulação das drogas. El País,Porto, 06 maio 2019. Disponível em:https://brasil.elpais.com/brasil/2019/05/02/internacional/1556794358_113193.html. Acesso em: 26 jun. 2021.

MARTINS, V. L. A política de descriminalização de drogas em Portugal. Serv. Soc. Soc., São Paulo, n. 114, p. 332-346, jun. 2013. Disponível em:http://www.scielo.br/scielo.php? script=sci_arttext\&pid=S010166282013000200007\&lng=en\&nrm=iso. Acesso em: 15 jul. 2020.

RODRIGUES NETO, M. A descriminalização do consumo de droga em Portugal- quinze anos depois. 2016. 115 f. Dissertação (Mestrado em Comunicação, Media e Justiça). Faculdade de Ciências Sociais e Humanas, Universidade Nova de Lisboa, Lisboa, 2016. Disponível em: https://run.unl.pt/handle/10362/20345. Acesso em: 15 jul. 2021. 